\title{
Crystal and molecular structure of bis(N,N-di-n-butyldithiocarbamato)- gold(III) bis(1,2-dicyanoethene-1,2-dithiolato)aurate(III)
}

\author{
J. H. NOORDIK AND P. T. BeURSKeNS \\ Crystallography Laboratory, Univer sity of Nijmegen, \\ Nijmegen, Netherlands
}

(Received 13 January 1971)

\begin{abstract}
The crystal and molecular structure of bis(N,N-di-n-butyldithiocarbamato)gold(III) bis(1,2-dicyanoethene-1,2-dithiolato)aurate(III), $\mathrm{Au}\left[\mathrm{S}_{2} \mathrm{CN}\left(\mathrm{C}_{4} \mathrm{H}_{9}\right)_{2}\right]_{2} \mathrm{Au}\left[\mathrm{S}_{2} \mathrm{C}_{2}(\mathrm{CN})_{2}\right]_{2}$, has been determined from a single-crystal $X$-ray diffraction study. The monoclinic cell, space group $P 2_{1} / c$, with $a=9.930(3)$, $b=12.517(3), c=15.632(3) \AA$ and $\beta=110.46(3)^{\circ}$, contains two formula units. Three-dimensional intensity data, up to $\theta=35^{\circ}$ were collected on an automatic diffractometer. Atomic parameters were refined by full-matrix least-squares methods to a conventional $R$ value of 0.04 for 1874 independent non-zero reflections. The structure consists of bis(di- $n$-butyldithiocarbamato)gold(III) cations and bis(1,2-dicyanoethene-1,2-dithiolato)aurate(III) anions. In both ions, the gold atom is in planar coordination with four sulphur atoms, the $\mathrm{Au}-\mathrm{S}$ bond lengths being 2.333(4) and 2.337(4) $\AA$ in the cation and 2.312(4) and 2.306(5) $\AA$ in the anion.
\end{abstract}

\section{Introduction}

During the work on the redox properties of dithiocarbamato and dithiolato complexes of transition metals at the Department of Inorganic Chemistry of this University, two complexes of composition $\mathrm{Au}(\mathrm{dtc})(\mathrm{mnt}),(\mathrm{dtc}=\mathrm{N}, \mathrm{N}$-di- $n$-butyldithiocarbamate, $\mathrm{mnt}=$ maleonitriledithiolate $=1,2$-dicyanoethene-1,2-dithiolate) were synthesised (van der Linden, 1971).

One complex appeared to be the ionic compound $\mathrm{Au}(\mathrm{dtc})_{2}{ }^{+} \mathrm{Au}(\mathrm{mnt})_{2}{ }^{-}$, whereas the other one is the mixed dithiocarbamato-dithiolato complex, $\mathrm{Au}(\mathrm{dtc})(\mathrm{mnt})$. To supply further information for discussion of the bonding in square-planar complexes, structure analysis of both compounds was initiated. In this paper the structure of the ionic species is reported; structural studies of the mixed ligand complex are in progress.

\section{Experimental}

The complex $\mathrm{Au}\left[\mathrm{S}_{2} \mathrm{CN}\left(\mathrm{C}_{4} \mathrm{H}_{9}\right)_{2}\right]_{2} \mathrm{Au}\left[\mathrm{S}_{2} \mathrm{C}_{2}(\mathrm{CN})_{2}\right]_{2}=\mathrm{Au}(\mathrm{dtc})_{2} \mathrm{Au}(\mathrm{mnt})_{2}$ crystallizes as well-formed brown crystals elongated along $a$. Preliminary Weissenberg photographs showed the crystals to be monoclinic, with space group $P 2_{1} / c$. From Pt-calibrated Weissenberg photographs around $a$ and

Copyright (C) 1971 Plenum Publishing Company Limited. No part of this publication may be reproduced, stored in a retrieval system, or transmitted, in any form or by any means, electronic, mechanical, photocopying, microfilming, recording or otherwise, without written permission of Plenum Publishing Company Limited. 
$b$, using $\mathrm{Cu} K \alpha$ radiation $(\lambda=1 \cdot 5418 \AA)$, application of a least-squares procedure yielded the unit cell dimensions: $a=9.930(3), b=12 \cdot 517(3), c=15.632(3) \AA, \beta=110 \cdot 46(3)^{\circ}, V_{c}=1820(1) \AA^{3}$. The calculated density of $1.98 \mathrm{~g} \mathrm{~cm}^{-3}$ with $Z=2$ agrees fairly well with the value of $2.02(2) \mathrm{g} \mathrm{cm}^{-3}$, from pycnometric measurements. A crystal of approximate dimensions $0.20 \times 0.15 \times 0.15 \mathrm{~mm}^{3}$, was mounted with $a$ along the $\varphi$-axis of a Nonius automatic diffractometer. Intensity data were measured with Zr-filtered Mo radiation (linear absorption coefficient $\mu=87.8 \mathrm{~cm}^{-1}$ ) using the moving countermoving crystal method with a scan speed of $0.3^{\circ} / \mathrm{min}$. After every fifteen reflexions, a reference reflexion was measured to detect and allow correction to be made for slow fluctuations in the primary beam. Of the 7990 independent reflexions theoretically attainable within the limit $\theta=35^{\circ}, 1874$ reflexions were measured above background. Absorption corrections were calculated according to the Busing \& Levy (1957) procedure, using $7 \times 7 \times 7$ volume components and six accurately-located boundary planes.

\section{Structure determination}

The reflexions $h k l$ with $h=2 n$ and $k+l=2 n$ are very strong relative to the remaining reflexions. The gold atoms were therefore placed at the special positions $000, \frac{1}{2} 00, \frac{111}{2} 2 \frac{1}{2}$ and $0 \frac{1}{2} \frac{1}{2}$. A Patterson synthesis showed sixteen $\mathrm{Au}-\mathrm{S}$ vectors around the origin. Based upon five possible sites indicated by the Patterson synthesis, several trial structures were tested but all failed to refine. A procedure was then developed for applying direct methods to centrosymmetric structures containing heavy atoms (Beurskens \& Noordik, 1971).

A modified Wilson plot was calculated to obtain approximate scale and overall isotropic temperature factors of the gold atoms and of the light atoms. The calculated contributions of the gold atoms were subtracted from the observed structure factors of the 1337 'strong' reflexions $h k l(h=2 n$, $k+l=2 n$ ) to obtain the contributions $F_{L}$, of the remaining atoms. As the sign of the structure factors of these 'strong' reflexions is determined by the gold atoms, both the magnitude and sign of $F_{L}$ for these reflexions are established. The observed structure factors of the remaining 538 'weak' reflexions do not have any contribution from the gold atoms (assuming the same sphericallysymmetrical electron-density distribution at the $\mathrm{Au}(1)$ and $\mathrm{Au}(2)$ sites) and, therefore, only the magnitude $\left|F_{L}\right|$ of these reflexions is known: $\left|F_{L}\right|=\left|F_{o b s}\right|$. The structure factors of the 'remainder structure' (i.e. total structure excluding Au atoms) were converted to normalized structure factors $E_{L}$ and the well-known Sayre-Zachariasen-Cochran triple product sign relationship $S_{h+h^{\prime}} \sim S_{h} . S_{h^{\prime}}$, was applied to reflexions with $\left|E_{L}\right|>1 \cdot 3$, to find the signs of the 'weak' reflexions.

A Fourier synthesis calculated with 549 reflexions (365 'strong' reflexions, 2 'weak' reflexions to fix the origin and 182 reflexions determined by the sign relationship) revealed the positions of all of the light atoms of the structure, except the hydrogen atoms. The structure factor calculation gave an $R$ value of $0 \cdot 12$. Refinement with anisotropic temperature factors for all atoms reduced this to 0.06 . A difference Fourier synthesis, using terms for which $\sin \theta / \lambda<0.35 \AA^{-1}$, showed all eighteen hydrogen atoms at expected positions. As the difference Fourier synthesis did not allow accurate location of the hydrogen atoms, they were placed at calculated positions (Table 2) (allowing rotation of the methyl groups to give the best fit with the difference Fourier synthesis) and allocated $B$ values of $4 \cdot 0 \AA^{2}$. Several more cycles of full-matrix anisotropic least-squares refinement with fixed hydrogen parameters reduced $R$ to a final value of 0.04 for 1874 observed reflexions. The separate final $R$ values for the 'strong' reflexions and for the 'weak' reflexions are 0.036 and 0.068 respectively. In the last cycle, the changes in all parameters were only a fraction of the standard deviations. The function that was minimized was $w\left(\left|F_{o}\right|-\left|F_{c}\right|\right)^{2}$. The weight $w$ for each reflexion was calculated according to $w=1 /\left(a\left|F_{o}\right|+b\right)$ with $a=-0.47$ and $b=40$ for $F_{o}<45, a=0.013$ and $b=18$ for $45<F_{o}<120$ and $a=0.30$ and $b=-17$ for $F_{o}>120$; these coefficients were based upon a plot of $\left(\left|F_{o}\right|-\left|F_{c}\right|\right)^{2}$ against $\left|F_{o}\right|$. The atomic scattering factors used were those of $\mathrm{Au}^{+}, \mathrm{S}, \mathrm{C}, \mathrm{N}$ and $\mathbf{H}$ with those for $\mathrm{Au}^{+}$corrected for anomalous scattering $\left(\Delta f^{\prime}, \Delta f^{\prime \prime}\right)$, using data from the International Tables for X-ray Crystallography. 
Table 1. Final atomic positional and thermal parameters for $A u(d t c)_{2} A u(m n t)_{2}$

The esd result from the least-squares refinement. The expression for the temperature factor is: $\exp -\left(\beta_{11} h^{2}+\beta_{22} k^{2}+\beta_{33} l^{2}+2 \beta_{12} h k+2 \beta_{13} h l+2 \beta_{23} k l\right)$.

\begin{tabular}{|c|c|c|c|c|c|c|c|c|c|}
\hline Atom & $x$ & $y$ & $z$ & $\beta_{11}$ & $\beta_{22}$ & $\beta_{33}$ & $\beta_{12}$ & $\beta_{13}$ & $\beta_{33}$ \\
\hline $\mathbf{A u}(1)$ & 0 & 0 & 0 & $0.0110(1)$ & $0.0046(1)$ & $0.0030(1)$ & $-0.0018(1)$ & $0.0027(1)$ & $-0-0003(1)$ \\
\hline $\mathrm{Au}(2)$ & $\frac{1}{2}$ & 0 & 0 & $0.0083(1)$ & $0.0049(1)$ & $0.0037(1)$ & $0.0005(1)$ & $0.0022(1)$ & $0-0004(1)$ \\
\hline $\mathbf{S}(1)$ & $0-0522(5)$ & $0 \cdot 1567(3)$ & $-0-0630(3)$ & $0.0147(6)$ & $0.0059(3)$ & $0.0029(2)$ & $-0.0025(4)$ & $0.0023(3)$ & $-0.0004(2)$ \\
\hline$S(2)$ & $0 \cdot 1391(5)$ & $0-1017(4)$ & $0.1250(3)$ & $0 \cdot 0146(6)$ & $0.0060(3)$ & $0.0030(2)$ & $-0 \cdot 0027(3)$ & $0.0028(3)$ & $-0.0003(2)$ \\
\hline$S(3)$ & $0.5354(5)$ & $0 \cdot 1045(4)$ & $0 \cdot 1280(3)$ & $0.0122(6)$ & $0.0068(3)$ & $0.0039(2)$ & $0.0000(4)$ & $0.0031(3)$ & $-0.0000(2)$ \\
\hline S(4) & $0 \cdot 6454(5)$ & $0 \cdot 1115(4)$ & $-0.0471(3)$ & $-0-0135(6)$ & $0.0064(3)$ & $0.0056(2)$ & $-0.0013(4)$ & $0.0049(3)$ & $-0.0004(2)$ \\
\hline $\mathbf{N}(1)$ & $0 \cdot 213(1)$ & $0 \cdot 288(1)$ & $0.069(1)$ & $0.010(2)$ & $0.005(1)$ & $0.003(1)$ & $0.000(1)$ & $0 \cdot 002(1)$ & $-0 \cdot 000(1)$ \\
\hline$N(2)$ & $0.741(2)$ & $0.342(2)$ & $0 \cdot 243(1)$ & $0.028(4)$ & $0.009(1)$ & $0.006(1)$ & $-0.003(2)$ & $0.002(2)$ & $-0.001(1)$ \\
\hline $\mathbf{N}(3)$ & $0.861(2)$ & $0.354(1)$ & $0.023(1)$ & $0 \cdot 015(3)$ & $0.009(1)$ & $0-007(1)$ & $-0.004(2)$ & $0.003(1)$ & $0.000(1)$ \\
\hline$C(1)$ & $0 \cdot 149(2)$ & $0 \cdot 198(1)$ & $0 \cdot 048(1)$ & $0 \cdot 010(2)$ & $0.005(1)$ & $0-003(1)$ & $-0.001(1)$ & $0.004(1)$ & $0 \cdot 000(1)$ \\
\hline$C(2)$ & $0 \cdot 214(2)$ & $0.365(1)$ & $-0-003(1)$ & $0.014(3)$ & $0.005(1)$ & $0 \cdot 004(1)$ & $-0.001(1)$ & $0 \cdot 004(2)$ & $0-001(1)$ \\
\hline$C(3)$ & $0.346(2)$ & $0 \cdot 347(1)$ & $-0.032(1)$ & $0.011(2)$ & $0 \cdot 007(1)$ & $0 \cdot 004(1)$ & $-0.002(1)$ & $0.003(1)$ & $-0.001(1)$ \\
\hline C(4) & $0 \cdot 337(2)$ & $0.419(2)$ & $-0 \cdot 111(1)$ & $0.011(2)$ & $0 \cdot 010(2)$ & $0 \cdot 005(1)$ & $0.001(2)$ & $0.004(1)$ & $0.002(1)$ \\
\hline$C(5)$ & $0.471(2)$ & $0.409(2)$ & $-0 \cdot 138(1)$ & $0.011(2)$ & $0 \cdot 011(1)$ & $0.003(1)$ & $-0.001(2)$ & $0.002(1)$ & $0.000(1)$ \\
\hline$C(6)$ & $0.296(2)$ & $0.315(1)$ & $0 \cdot 166(1)$ & $0 \cdot 010(2)$ & $0.006(1)$ & $0.002(1)$ & $-0.001(1)$ & $0.000(1)$ & $-0 \cdot 001(1)$ \\
\hline$C(7)$ & $0.206(2)$ & $0.367(1)$ & $0.215(1)$ & $0.015(3)$ & $0.007(1)$ & $0.004(1)$ & $0.001(2)$ & $0.003(1)$ & $-0.000(1)$ \\
\hline$C(8)$ & $0.153(2)$ & $0.479(1)$ & $0.185(1)$ & $0-014(2)$ & $0.007(2)$ & $0.004(1)$ & $-0 \cdot 001(1)$ & $0.004(1)$ & $-0.001(1)$ \\
\hline C(9) & $0.069(2)$ & $0 \cdot 527(1)$ & $0 \cdot 241(1)$ & $0.013(2)$ & $0.009(2)$ & $0 \cdot 005(1)$ & $-0 \cdot 001(1)$ & $0.002(1)$ & $-0.003(1)$ \\
\hline$C(10)$ & $0.656(2)$ & $0 \cdot 200(1)$ & $0 \cdot 114(1)$ & $0.011(2)$ & $0.005(1)$ & $0.005(1)$ & $0.001(1)$ & $0 \cdot 002(1)$ & 0-001(1) \\
\hline$C(11)$ & $0.670(2)$ & $0 \cdot 205(1)$ & $0.042(1)$ & $0.008(2)$ & $0.005(1)$ & $0 \cdot 004(1)$ & $0 \cdot 000(1)$ & $0.002(1)$ & $0.001(1)$ \\
\hline$C(12)$ & $0.701(2)$ & $0.277(2)$ & $0 \cdot 187(1)$ & $0.014(3)$ & $0.007(1)$ & $0.006(1)$ & $0 \cdot 000(1)$ & $0.002(1)$ & $0-001(1)$ \\
\hline$C(13)$ & $0.791(2)$ & $0 \cdot 287(1)$ & $0.033(1)$ & $0.012(2)$ & $0.005(1)$ & $0.006(1)$ & $0 \cdot 001(1)$ & $0.003(1)$ & $-0.000(1)$ \\
\hline
\end{tabular}

Table 2. Unrefined hydrogen atom positional parameters $\left(B=4 \cdot 0 \AA^{2}\right)$

The first index identifies the parent carbon atom.

\begin{tabular}{|c|c|c|c|c|}
\hline Atom & $x$ & $y$ & $z$ & \\
\hline $\mathbf{H}(21)$ & 0.21 & 0.45 & 0.02 & \\
\hline $\mathbf{H}(22)$ & $0 \cdot 11$ & 0.36 & -0.07 & \\
\hline H(31) & 0.35 & $0 \cdot 26$ & -0.06 & \\
\hline $\mathbf{H}(32)$ & 0.45 & $0 \cdot 36$ & 0.02 & \\
\hline $\mathrm{H}(41)$ & 0.34 & 0.50 & -0.09 & \\
\hline $\mathbf{H}(42)$ & $0 \cdot 24$ & 0.41 & $-0 \cdot 17$ & \\
\hline $\mathbf{H}(51)$ & 0.46 & 0.47 & -0.18 & \\
\hline $\mathbf{H}(52)$ & 0.56 & 0.40 & -0.08 & \\
\hline $\mathbf{H}(53)$ & 0.46 & 0.33 & -0.18 & \\
\hline $\mathbf{H}(61)$ & 0.38 & $0 \cdot 37$ & 0.17 & \\
\hline$H(62)$ & 0.35 & 0.24 & $0 \cdot 21$ & \\
\hline $\mathbf{H}(71)$ & $0 \cdot 25$ & 0.37 & 0.29 & \\
\hline$H(72)$ & $0 \cdot 10$ & 0.32 & $0 \cdot 20$ & \\
\hline $\mathbf{H}(81)$ & 0.09 & 0.48 & $0 \cdot 11$ & \\
\hline$H(82)$ & 0.25 & 0.53 & 0.19 & \\
\hline$H(91)$ & $0 \cdot 13$ & 0.48 & $0 \cdot 30$ & \\
\hline $\mathrm{H}(92)$ & -0.04 & 0.49 & 0.22 & \\
\hline$H(93)$ & 0.06 & 0.61 & $0 \cdot 24$ & \\
\hline
\end{tabular}


Calculations were performed on an IBM 360/50 computer, using programs written by Busing, Martin \& Levy (1962), Johnson (1965), Ahmed \& Pippy (1968) and data reduction programs written at this laboratory. Programs for the application of direct methods, written by Dewar \& Stone (1966) were modified by one of the authors (J.H.N.) for the special procedure described in this paper.

\section{Description and discussion}

Interatomic distances and angles, computed from the parameters of Table 1, are given in Fig. 1. Projections of the structure along $b$ and $c$ are presented in Fig. 2 and Fig. 3 respectively. The $\mathrm{Au}(\mathrm{dtc})_{2}{ }^{+}$ and $\mathrm{Au}(\mathrm{mnt})_{2}-$ ions are illustrated in Fig. 4.
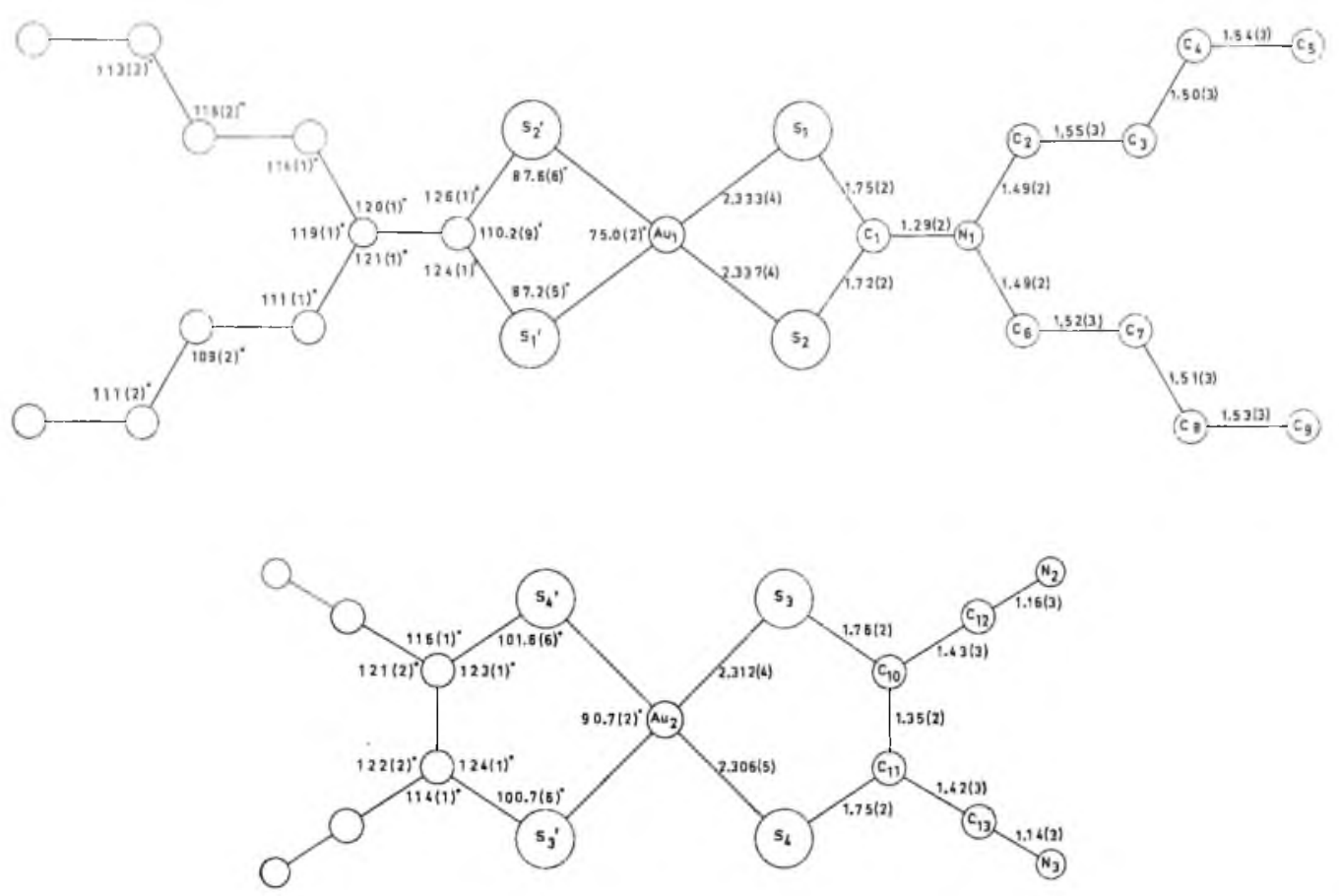

Fig. 1. Geometry of $\mathrm{Au}(\mathrm{dtc})_{2}{ }^{+}$(top) and $\mathrm{Au}(\mathrm{mnt})_{2}{ }^{-}$(bottom) with esd in parentheses.

In the anion, as well as in the cation, the gold atom is situated at a centre of symmetry and is in planar coordination with four sulphur atoms. Anions and cations alternate in strings in the direction of the $a$ axis, with an angle of $36.3^{\circ}$ between the coordination planes of neighbouring ions. Parallel strings are related by two-fold screw-axes. No interionic contacts less than those expected from van der Waals radii occur.

In the $\mathrm{Au}(\mathrm{dtc})_{2}{ }^{+}$cation, the $\mathrm{S}(1)$ - $\mathrm{Au}(1)-\mathrm{S}(2)$ angle is $75.0(2)^{\circ}$ and the two symmetry independent $\mathrm{Au}-\mathrm{S}$ bond lengths are $2 \cdot 333(4)$ and $2 \cdot 337(4) \AA$. The ion is nearly planar, except for the butyl chains. The equation of the least-squares plane through $\mathrm{Au}(1), \mathbf{S}(1), \mathbf{S}(2)$ and $\mathrm{N}(1)$ is given by: $0.9050 X-0.4224 Y-0.0515 Z=0$. No atoms deviate by more than one standard deviation from this plane. The distances of $C(2)$ and $C(6)$ from this plane are 0.01(2) and 0-05(2) $\AA$ respectively. Bond lengths and angles in the cation are in close agreement with those found in other structures 
containing the $\mathrm{Au}(\mathrm{dtc})_{2}{ }^{+}$ion (Beurskens, Blaauw, Cras \& Steggerda, 1968; Beurskens, Cras \& van der Linden, 1970; Cras, Noordik, Beurskens \& Verhoeven, 1971).

The coordination of the gold atom in the $\mathrm{Au}(\mathrm{mnt})_{2}{ }^{-}$anion is nearly square-planar, the $\mathrm{S}(3)-\mathrm{Au}(2)-\mathrm{S}(4)$ angle being $90 \cdot 7(2)^{\circ}$ and the two $\mathrm{Au}-\mathrm{S}$ bond lengths being 2.312(4) and 2.306(5) $\AA$. The intra-ligand $\mathbf{S}(3)-\mathbf{S}(4)$ distance and the inter-ligand $\mathbf{S}(3)-S\left(4^{\prime}\right)$ distance are 3.284(7) and $3.246(7) \AA$ respectively. The equation of the least-squares plane through all atoms of the anion

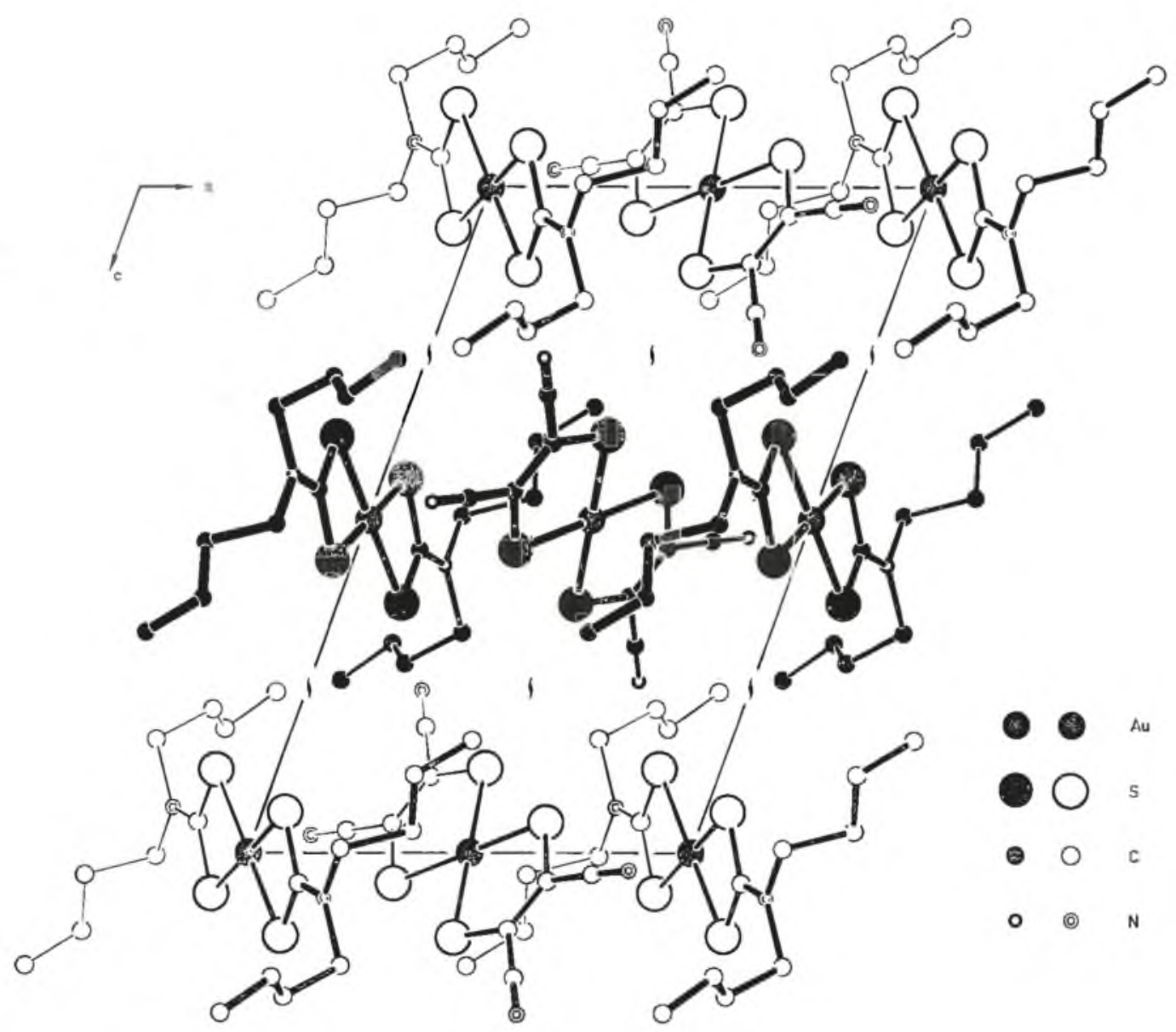

Fig. 2. Projection of the structure along $b$. Gold atoms are on centres of symmetry and two-fold screw axes are indicated. White ions are at $y=0$ and black ions are at $y=\frac{1}{2}$.

is given by: $-0.6581 X+0.5607 Y-0.5026 Z+3.2673=0$. The largest distance from this plane, -0.09 (2) $\AA$, is found for the nitrogen atom $N(2)$.

Bond lengths and angles in the anion agree to within one or two standard deviations with those found in the comparable $\mathrm{Au}\left(\mathrm{S}_{2} \mathrm{C}_{2}\left(\mathrm{CF}_{3}\right)_{2}\right)_{2}-$ ion (Enemark \& Ibers, 1968) except for possible signifcant differences in the $\mathrm{Au}-\mathbf{S}$ distances and $\mathbf{S}-\mathbf{A u}-\mathbf{S}$ angle. Similar differences are found in comparable Co and Ni complexes as can be seen in Table 3. From the available data it would appear that the $\mathbf{S}-$ metal $-\mathbf{S}$ angle in the dithiolato system is more sensitive to a change of substituents than are the bond lengths. 


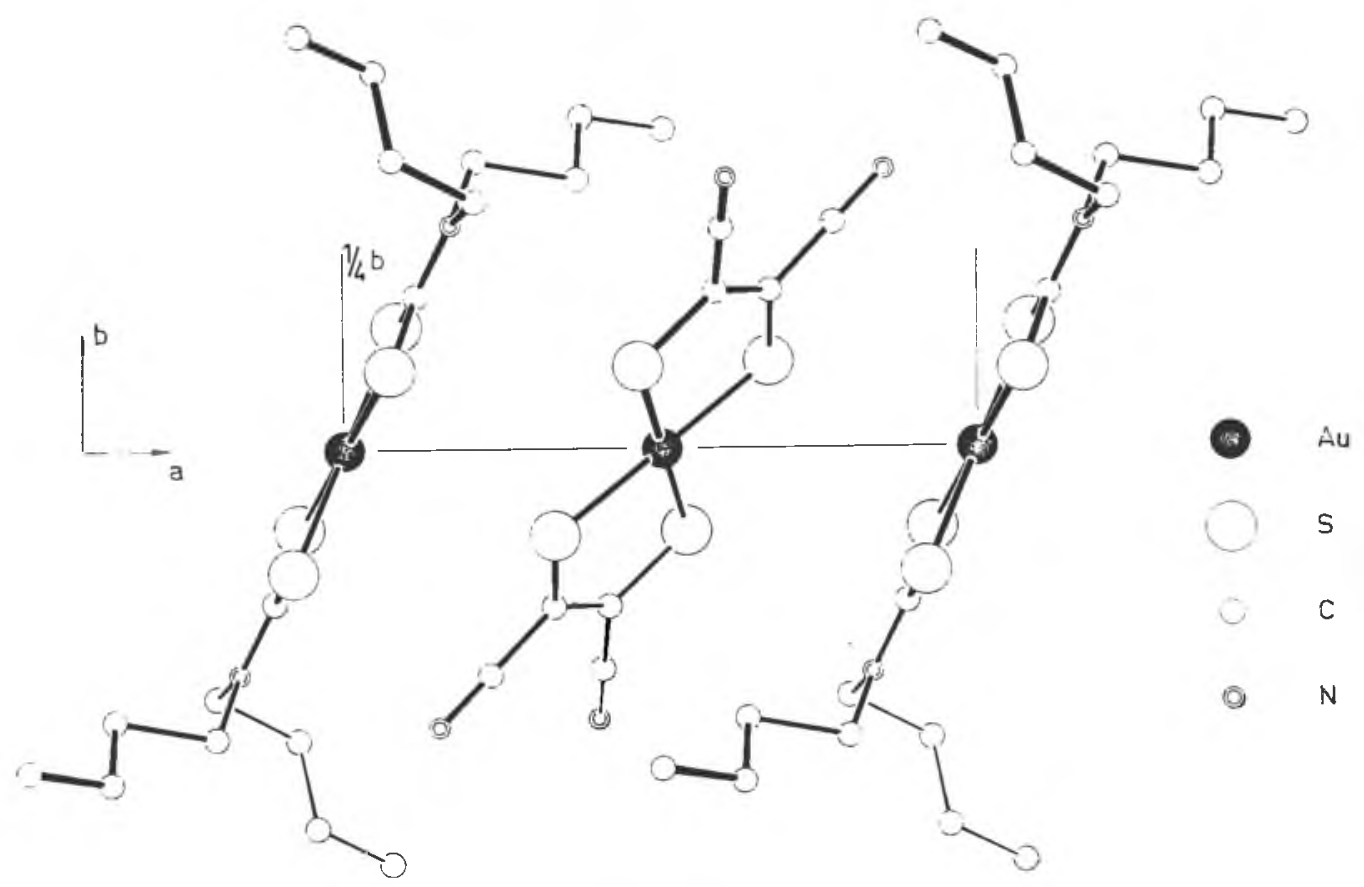

Fig. 3. Projection of the structure along $c$. Only one string of ions (at $z=0$ ) is given.
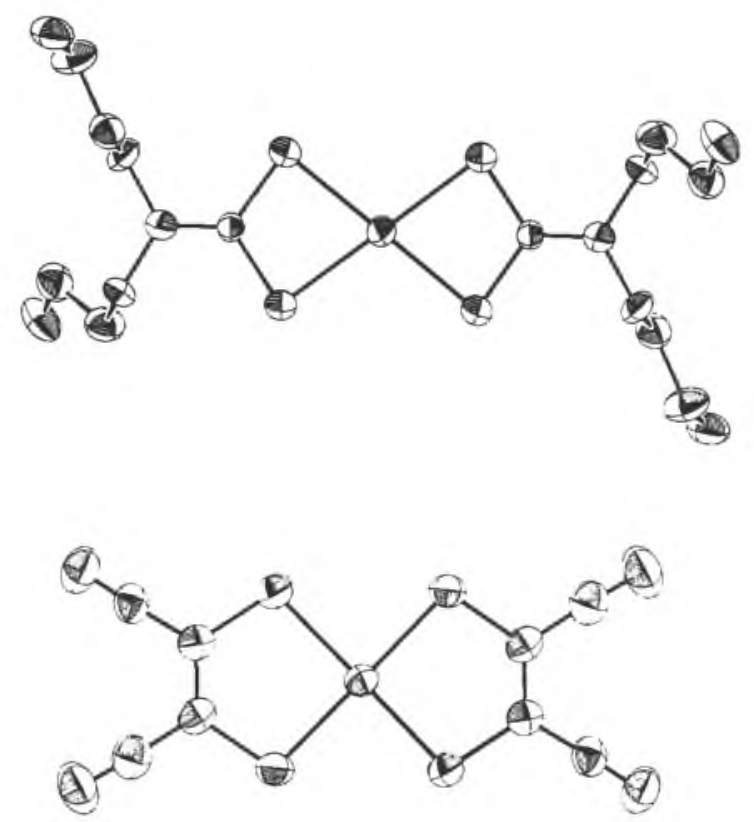

Fig. 4. View of the $\mathrm{Au}(\mathrm{dtc})_{2}{ }^{+}$ion (top) and the $\mathrm{Au}(\mathrm{mnt})_{2}{ }^{-}$ion (bottom), illustrating the thermal anisotropy. 


$$
\mathrm{Au}(\mathrm{dtc})_{2}^{+} \mathrm{Au}(\mathrm{mnt})_{2}^{-}
$$

The significant difference in $\mathrm{Au}-\mathrm{S}$ bond lengths in the cation and the anion, again shows that metal-ligand $\pi$-bonding is more substantial in complexes of 1,2-dithiolato ligand systems than it is in complexes of 1,1-dithiolato ligand systems (Eisenberg, 1970).

Table 3. Interatomic distances and angles* within the ethene-1,2-dithiolato ligands of some transition-metal complexes

\begin{tabular}{lllllll}
\hline & & $\mathrm{M}-\mathrm{S}(\AA)$ & $\mathrm{S}-\mathrm{C}(\AA)$ & $\mathrm{C}=\mathrm{C}(\AA)$ & $\mathrm{S}-\mathrm{M}-\mathrm{S}\left({ }^{\circ}\right)$ & $\mathrm{Ref}$. \\
\hline$\pi-\mathrm{C}_{5} \mathrm{H}_{5}-\mathrm{CoS}_{2} \mathrm{C}_{2} \mathrm{R}_{2}$ & $\mathrm{R}=\mathrm{CF}_{3}$ & $2 \cdot 08(1)$ & $1 \cdot 74(5)$ & $1 \cdot 48(5)$ & $92 \cdot 2(2)$ & $a$ \\
& $\mathrm{R}=\mathrm{CN}$ & $2 \cdot 117(2)$ & $1 \cdot 702(6)$ & $1 \cdot 364(10)$ & $93 \cdot 2(1)$ & $b$ \\
$\mathrm{Ni}\left(\mathrm{S}_{2} \mathrm{C}_{2} \mathrm{R}_{2}\right)_{2}{ }^{-}$ & $\mathrm{R}=\mathrm{CF} F_{3}$ & $2 \cdot 136(3)$ & $1 \cdot 70(1)$ & $1 \cdot 40(2)$ & $91 \cdot 4(1)$ & $c$ \\
$\mathrm{Au}\left(\mathrm{S}_{2} \mathrm{C}_{2} \mathrm{R}_{2}\right)_{2}{ }^{-}$ & $\mathrm{R}=\mathrm{CN}$ & $2 \cdot 147(1)$ & $1 \cdot 715(2)$ & $1 \cdot 355(5)$ & $92 \cdot 3(1)$ & $d$ \\
& $\mathrm{R}=\mathrm{CF}{ }_{3}$ & $2 \cdot 288(4)$ & $1 \cdot 77(1)$ & $1 \cdot 30(2)$ & $89 \cdot 7(2)$ & $e$ \\
& $\mathrm{R}=\mathrm{CN}$ & $2 \cdot 309(4)$ & $1 \cdot 75(1)$ & $1 \cdot 35(2)$ & $90 \cdot 7(2)$ & $f$ \\
\hline
\end{tabular}

* Average of symmetry-independent values.

(a) Baird \& White (1966)

(b) Churchill \& Fennessey (1968).

(c) Wing \& Schlupp (1970).

(d) Fritchie (1966).

(e) Enemark \& Ibers (1968).

(f) This work.

\section{References}

Ahmed, F. R. \& Pippy, M. E. (1968) NRC Crystallographic Computer programmes.

Baird, H. W. \& White, B. M. (1966) J. Amer. Chem. Soc. 88, 4744.

Beurskens, P. T. \& Noordik, J. H. (1971) Acta Crystallogr. A27, 187.

Beurskens, P. T., Blaauw, H. J. A., Cras, J. A. \& Steggerda, J. J. (1968) Inorg. Chem. 7, 805.

Beurskens, P. T., Cras, J. A. \& van der Linden, J. G. M. (1970) Inorg. Chem. 9, 475.

Busing, W. R., Martin, K. O. \& Levy, H. A. (1962) Fortran least-squares Program (ORFLS).

Churchill, M. R. \& Fennessey, J. P. (1968) Inorg. Chem. 7, 1123.

Cras, J. A., Noordik, J. H., Beurskens, P. T. \& Verhoeven, A. M. (1971) J. Cryst. Mol. Struct. 1, 155.

Dewar, R. B. K. \& Stone, A. L. (1966) Fortran programmes for the application of direct methods in centric crystals. University of Chicago.

Enemark, J. H. \& Ibers, J. A. (1968) Inorg. Chem. 7, 2636.

Eisenberg, R. Progress in Inorganic Chemistry, Vol 12 (Interscience Publishers, New York, 1970, p. 295).

Fritchie, C. J. (1966) Acta Crystallogr. 20, 107.

International Tables for $X$-Ray Crystallography, Vol. III (Kynoch Press, Birmingham, England, 1962).

Johnson, C. K. (1965) Fortran thermal-ellipsoid plot program (ORTEP).

van der Linden, J. G. M. (1971) Rec. Trav. Chim. (in press), and Inorg. Chim. Acta, 5, 254.

Wing, R. M. \& Schlupp, R. L. (1970) Inorg. Chem. 9, 471.

National Lending Library Supplementary Publication No. 60031 contains 3 pages of structure factor tables on 1 microfiche. 